\title{
POLICY-MAKING FOR REAL: POLITICS AND PROGRESS IN SOUTH AFRICAN HEALTH CARE
}

\author{
A. Fourie and H.C.J. van Rensburg
}

\section{INTRODUCTION}

Problems have been accumulating in South African health care for well over three centuries yet when it comes to resolving the crisis by means of appropriate policy measures, one becomes aware of the powers at play and the interests at stake in maintaining the status quo, thus obstructing much initiative in the process of reform.

In this article, the problematic nature of health reform and health policy-making in a changing South Africa comes under critical review, its aim being to argue the case for progressive reform alternatives as solutions to South Africa's health care problems. In answer to Coovadia's $(1991,23)$ belief that "... choices have to be made on basis of reason and not outdated ideology", this exercise may be regarded as an endeavour to present a systematic and impartial exposition of principles and requirements needed for health reform and health policy-making in South Africa. The main problems in South African health care will be stated with the purpose of illustrating and emphasising the need for reform in the health sector. This leads to an exposition of the requirements, principles and strategies to be incorporated in a health policy according to which South Africa's health care problems can be appropriately addressed and the health care system reformed. The final section of the article comprises a reflection on the prospects and feasibility of fundamental, progressive reform against the background of existing power relations in the South African health sector.

\section{THE NEED FOR PROGRESSIVE HEALTH REFORM: PROBLEMS TO BE ADDRESSED}

\section{Shortages in South African health care}

Perhaps most manifest problems in South African health care today concern resources. Specifically, shortages of manpower, physical facilities and finance (i.e., primary shortages), and the maldistribution, mis-allocation and mal-utilisation of resources (i.e., secondary shortages) are all apparent.

With regard to labour power, South Africa has to contend with primary shortages in almost all categories of professional and non-professional health workers. In many cases, personnel: population ratios indicating the availability of labour power in various categories of health workers in South Africa compare unfavourably with minimum-criteria set by the WHO and fall far short of comparable ratios in other middle-income, industrialised countries. The exception is nurses - South Africa boasts one of the highest total nurse: population ratios in the world, namely 49:10000 (Cf. Cooper et al. 1988a, 78; Department of National Health and Population Development 198835 \& 37; Dewar 1990, 4-5; Republic of South Africa 1988/89, 514; 1990/91, 155). As regards doctors, dentists, pharmacists and supplementary health workers, quite the opposite prevails. Bear in mind, however, that already scarce labour power is divided unevenly between the private and public sectors of health care - the former providing occupation for an increasing number of health workers as working conditions in the overburdened public sector become difficult. The ensuing maldistribution of personnel between the respective sectors eventually finds reflection in discrepancies in the labour power available to various socio-economic and racial groups and in different geographical areas; it is clear that in this respect the private sector, catering for the needs of a privileged urbanised clientele, comes off best. This particular discrepancy, which permeates all aspects and spheres of health care in South Africa, may be attributed to the fact that whites have by far the largest share of health insurance in this country. The health insurance industry was in fact established by De Beers Consolidated Mines in 1889 to ensure that its white employees and their dependents could avail themselves easily of private health services which were abundant in South Africa's main centre of industrial development at the time (Van Rensburg et al. 1992, 218). In 1989, almost $70 \%$ of whites in South Africa had health insurance, as against approximately $30 \%$ of each of the coloured and Asian populations and $6,5 \%$ of all Africans (Van Rensburg et al. 1992, 228). The problem of primary personnel shortages in the South African health care system thereby acquires a secondary dimension within which race and privilege feature prominently.

Primary shortages also occur with regard to institutional resources of health care in South Africa, i.e. hospital and clinic facilities. As clinic services are provided by local authorities and are only partially subsidised from the national public health budget, the nature, extent and quality of these services vary according to the size and wealth of the local populations concerned. Local authorities serving densely populated, relatively affluent communities are in a better position to provide more comprehensive services of a higher standard than those serving underprivileged communities and it is consequently difficult to come to any single, decisive conclusion regarding the standard of clinic services in South africa. Savage \& Benatar (1990, 154) consider the whole range of primary, preventive and community-based health services in South Africa to be generally inadequate and counter-productive: "There is a marked dominance of spending on curative medicine over preventive medicine. This means insufficient resources are being injected into a badly planned [and already financially impaired] health care system that places little emphasis on primary and community health services. One consequence is that the resources and facilities in even the best hospitals are under pressure when, with better planning, demands for health care at the tertiary level could have been met more 
effectively and less expensively at primary and secondary health care levels." The non-white population of South Africa, whose epidemiological profiles reveal a prevalence of acute, infectious diseases and who could, by implication, benefit most from primary health care services, eventually suffers the detrimental consequences of these distorted priorities.

As regards hospital facilities, the provision of hospital beds in South Africa has deteriorated in recent years. In 1989 the total hospital bed: population ratio was $3,7: 10000$, as against $4,4: 1000$ in the mid-1970s (Benatar 1988, 23-24; Department of National Health and Population Development 1988, 25; 1991, 77; Naylor 1988, 1157; Republic of South Africa 1990/91, 156). Considering the general inadequacy of primary health services in South Africa, this indicates a shortage of hospital beds if the international criterion requiring a minimum of 4 beds per 10000 of populations deprived of adequate primary care is applied. This shortage of hospital beds manifests itself to varying degrees in the respective sectors of health care and consequently also in the different population groups. Considering the fact that only about $20 \%$ of the South African population has access to private hospital services by virtue of medical scheme membership, the provision of hospital beds in the private sector can be regarded as superfluous. The international norm requiring at least 2 hospital beds per 1000 of populations which are adequately provided with primary health services is by far exceeded in this sector - in fact, the hospital bed:population ratio concerned was 4:10000 in 1990. Meanwhile, the vast majority of South Africans are dependent on public hospital services the inadequacy and insufficiency of which are clearly shown by bed occupancy rates of up to $151,4 \%$ in some public hospitals ${ }^{1}$. Particularly significant is the fact that severe over-occupancy and over-utilisation of hospital beds occur mainly in public hospitals serving non-white communities (Van Rensburg et al. 1992, 244-245).

\section{Financial affairs in the health sector}

With regard to financial resources, both state and household budgets are stretched in the attempt to keep up with the increasing demand for more and better health services from a rapidly expanding consumer population on the one hand and high-tech, specialised medicine on the other hand.

A review of expenditure figures reveals that the real increase in per capita-health expenditure in the private sector has cost the consumer severely. Significant real increases in an already relatively high per capita-expenditure rate in the private health sector and the marked escalation of the cost of health insurance clearly are related. In 1987, per capita-health expenditure in the private sector amounted to R555. It has increased in real terms (as measured against 1985-price indices) with 5,9\% from $1987 / 88$ to $1988 / 89$ and with a further $10,7 \%$ in the following year (Department of National Health and Population Development 1991, 76). Meanwhile, the cost of health insurance has been increasing at more than twice the rate of inflation since the beginning of the $1980 \mathrm{~s}$ (Broomberg 1980s et al. 1990, 139; Benatar 1991, 33; Centre for Health Policy 1990b, 2; Naylor 1988, 1160; Van Rensburg et al. 1992, 231). The problem concerning financial resources in the private sector thus relates to uncontrollable cost escalations and the increasing unaffordability of health care, which seem to be endemic to the combination of free-market mechanisms of financing and the private provision of care. To be more specific, the following factors lead, in mutually reinforcing relation, to increases in the cost of health care in the private sector:

- a commercialised and essentially utilitarian approach towards health care;

- third-party financing arrangements and the guaranteed remuneration of providers on a fee-for-service basis;

\section{- consumer ignorance;}

- supplier-induced demand, i.e. physicians' ability to generate and regulate the need and demand for their own services (Cf. Maynard 1986, 1163; Rosen 1989, 457);

- professional autonomy in an unregulated market and;

- the universal, though unpredictable and uncertain nature of the need for care.
Despite increase in the cost of health insurance and private health care, the private sector continues to cater for the needs of consumers (mainly whites) who still can afford claim to the standard of care offered by private providers and private health care institutions.

The public sector is experiencing severe financial shortages. Although public health expenditure has increased in real terms in recent years, the effect of these increases is neutralised by:

- the high inflation rate;

- the rapidly increasing size, due to a high natural rate of increase (birthrate), among the public sectors's clientele;

- the growing number of patients who find the private sector inaccessible as health insurance becomes increasingly unaffordable and who are consequently thrown upon public health services.

At the same time, however, considerable amounts of money still are being spent on the administration of a cumbersome and wasteful public health bureaucracy. In contrast with the per capita-expenditure rate of R555 in the private sector in 1987 , the comparable rate in the public sector amounted to only R159 - increasing in real terms by a limited $3,6 \%$ per annum ever since (Department of National Health and Population Development 1991, 76). It appears that the administration of the public health care system absorbs a disproportionately large amount of resources and that political decision-making may contribute to a high rate of public health expenditure. Kelly (1988, 117) calculated that the costs incurred by the duplication of services and facilities resulting from the differentiation between "own" and "general" affairs amounts to approximately R800 million per annum. It has been estimated that of every rand spent in the public health sector, twelve cents go towards the "administration of apartheid" (Cf. De Beer 1988, 9; Savage 1986). The bottom line is that "... the duplication of everything from administrative structures to stationary, the multiplication of ministerial motor cars, the need for extra staff and the existence of three separate structures to co-ordinate between all the fragments of the health services must cost the tax payer several million rand per year,

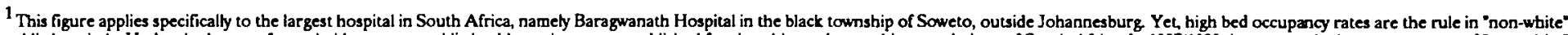

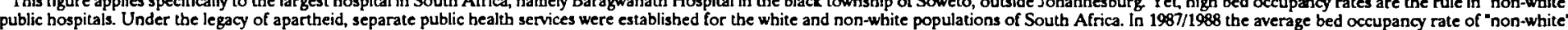

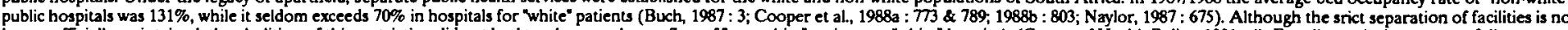

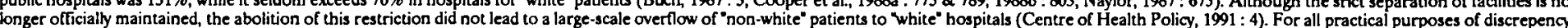
regarding the availability of public hospitals facilities between population groups still holds.
} 
with no benefits in terms of additional services" (Centre for the Study of Health Policy 1988, 9; cf. Cooper et al. 1989, 2-3).

While problems concerning financial resources in the private sector stem from the inherent nature of private health care provision in a free market, the problems concerning financial resources in the public sector seem rather to be the result of inefficient organisation and lack of co-ordination. Although these inadequacies are surmountable, the clientele of the public sector (mainly non-whites) have to contend with the detrimental effects they have on the quality and quantity of services and facilities available to them.

\section{The latent problems in South African health care}

To appreciate the complexity of South Africa's health care problems, one has to bear in mind that the aforementioned problems are manifest in nature; they are the symptoms of underlying problems and deficiencies which must be addressed if the health care crisis is to be resolved. In the final analysis, many of the manifest problems concerning shortages of resources and inequalities in the distribution of resources, with consequent discrepancies in the availability, accessibility, acceptability and affordability of services and facilities for the various groups comprising the South African population, seem to be the result of:

- the structural fragmentation of the health care system itself (This refers to the first-order pluralisation between the private and public sectors and the second-order fragmentation among various independent organisations, bodies and institutions of health care provision within the respective sectors);

- the inevitable lack of co-ordination and co-operation among the various composing parts of this highly fragmented system;

- the leaving, to a large extent, of the provision of health care to market forces and private providers whose main objective is profit making;

- the strong impression which the legacy of apartheid has left on South African health care and;

- the distortions caused by the domination of the health care system by the medical profession.
Yet, standing above all these problems and contributing to their existence is perhaps the most distinct characteristic of the South African health care system, namely the absence of a binding and enforceable national health policy. As such, the system rightfully can be regarded as a ship adrift in a sea of needs, demands and requirements. In this view, progressive reform clearly requires the issues of structural integration and national health policy-making to be addressed if we are to find solutions for its health care problems. There is a need for an integrated system of health care in South Africa, which could, within the framework of a national health policy, provide effective, appropriate health care of an acceptable nature, standard and quality at the lowest possible cost and price according to the real health needs and demands of the entire population in its full diversity. In short, this country is in need of a new, socially accountable health care system that would be attuned to the real demands, needs and abilities of its total clientele on the one hand and which, on the other hand, would find its legitimacy in the approval/acceptance of this clientele (Van Rensburg et al. 1992, 365).

\section{THE PRINCIPLES AND REQUIREMENTS OF PROGRESSIVE REFORM IN SOUTH AFRICAN HEALTH CARE:}

Socially accountable health care is based on acknowledgement of health care as a basic human right, a social good and a public (collective) affair. Egalitarian values such as altruism, equality, equity and justice would consequently feature prominently in a policy that will have to embody these principles in a socially accountable health care dispensation in South Africa. Socially accountable health care ultimately rests on the following basic principles. ${ }^{2}$

\section{- Availability: Geographically,} strategically and logistically the full spectrum of services and facilities preventive, curative and rehabilitative - should be so distributed as to enable people to avail themselves of them as the need arises.

- Appropriateness and relevance: The kind of services and facilities supplied should bear a clear relation to and should co-ordinate with the real health needs of communities dependent upon these services and facilities as sources of health care.
- Acceptability: The services and facilities being supplied should be personally and socio-culturally acceptable for the members of a particular community. Variables such as the level of urbanisation, industrialisation, modernisation, westernisation and education of the clientele, as well as diverse views and beliefs regarding health, disease and health care should be acknowledged and taken into account in the planning and provision of care.

- Adaptability and flexibility: Constantly changing health needs of various communities necessitate regular re-assessment of the appropriateness of the care supply in those communities. The care supply should be re-attuned and newly synchronised according to the evolving needs and demands of communities.

- Accessibility:

Geographical, financial, racial, political, infrastructural and other barriers should not be allowed to obstruct the need-related access to health care.

- Affordability: No individual should be denied or deprived of basic health care because of inability to pay for it. Neither should the subsidisation and financing of health care consume disproportionately large amounts of the state's welfare expenditure.

Since private sector seems unable to provide for cost-effective and comprehensive health needs of the total population, and the government seems unable to do so in an effective and equitable manner, health reform requires visionary thinking with regard to the introduction of alternative arrangements. The existing health care system will have to be restructured if the requirements of socially accountable health care are to be met. The focus and emphasis in this process of structural reform should be on the following:

- first of all, the exfoliation and elimination of fragmentation in the health care system;

- secondly, the introduction and encouragement of appropriate orientations towards health care in order to ensure that the real health needs of the total population are equally, comprehensively and appropriately addressed;

\footnotetext{
${ }^{2}$ These are derived from principles stipulated by, amongst otber, Coe 1978, 413-415; Elling 1974; Prescot \& De Ferranti, 1985; Twaddle 1982 : 355 . Also cf. Van Rensburg et al., 1992 : 364-365 in this regard.
} 
- thirdly, the accomplishment of managerial and organisational efficiency to ensure optimal utilisation of available resources and personnel in the best interest of the clientele (Cf. Centre for the Study of Health Policy 1989, 5; De Beer 1988, 4).

These objectives require different principles and practices of planning, control, organisation and financing than those currently in operation. Amongst others, they require:

- a fundamental reconsideration of the rationale of health care and its provision;

- a re-orientation in the training of health workers;

- community involvement and deliberation in the planning of health care so that the care supply may be synchronised with actual needs and demands of various communities;

- organisation of the care supply on a regional basis, yet within the framework of an enforceable, national health policy;

- consolidation of responsibilities regarding the planning, control, financing and provision of health care into a single, representative and capable authority with no primary financial interest or commercial motive in the provision of care.

Against this background a blueprint for socially accountable health care entails the following:

Planning and organising for socially accountable health care

As regards planning, socially accountable health care requires a community-based, democratised approach and establishment of basic planning units ("health care communities") is crucial in this regard. For planning purposes, communities should constitute groups of people who are in comparable political-economic, social and geographical circumstances and who display fairly similar demographic and epidemiological profiles. The basic contention is that such factors have bearing on the need and demand for care, and by planning health care accordingly, an appropriate care supply can be ensured. The rationale for community-based planning lies in its potential to provide an appropriate combination of services and facilities according to the real needs and demands for health care as displayed by smaller "health care communities" - thus in economising by eliminating excessive or unnecessary provision (Cf. Allan \& Hall 1988, 31; Tannen 1980, 128-129).

While the need for health care can be derived from various measurable and standardised health indicators, the demand for health care can be only established by consulting communities to establish their views, beliefs and expectations regarding health and health care. Such consultation could reveal valuable information about what various communities consider necessary, affordable, appropriate and acceptable in terms of health care; it should give, too, an indication of which services various communities would actually utilise. Since community-based planning leads to equal provision of care to communities with relatively comparable needs and therefore also enhances the equal provision of care to different communities which are equally exposed to similar health risks, the underlying principles of equity and equality in health care are honoured (Cf De Beer 1988, 5; Klopper et al. 1989, 209; Price 1987, 51 \& 62). With particular reference to planning of health care in South Africa, Klopper et al. (1989:210) are of the opinion that "... [a] number of regions determined by administrative efficiency will have to be created to implement resource allocation policy. Appropriate administrative structures are therefore sine qua non for the distribution of resources to ensure equity. Regionalisation is the method by which it is best achieved." Note, however, that this requires the health planning process in South Africa to be reversed from the prevailing authoritarian process of imposition from above to a democratised process of consultation from the bottom up (Centre for Health Policy 1990, 2). It also requires the boundaries of "health care communities" to remain flexible - in other words to be expanded or seceded according to varying and continuously changing needs and demands of clientele.

Existing control mechanisms in South African health care are unsuitable and inappropriate for the provision of socially accountable health care. In stark contrast to the fragmented, responsibility currently characterising the South African health care system, stands the need for a central controlling body invested with responsibility of formulating an appropriate national health policy in accordance with the criteria of socially accountable health care; such a body would control the implementation of policy. Klopper et al.
$(1989,209)$ clarify the apparent anomaly between regionalised planning and centralised control as follows: "The contention is that a central co-ordinating health authority is essential to formulate policy and ensure uniform implementation in regional authorities within the national framework. Without an effective central planning and monitoring authority, autonomous regions could pursue laissez-faire and sectorially motivated policies, thereby creating interregional disparities and defeating the purpose of ensuring equity of health care in South Africa." A responsible, representative authority with mandate to accomplish fundamental reform through critical reconsideration of prevailing practices in health care therefore should orchestrate and control the entire reform process. Its basic premise and main objective should be to transform the current health care policy, into a pro-active health policy in the true sense of the word, implying that the real needs and demands of the total clientele should apply as the overriding principle in deployment and allocation of resources.

\section{The financing of socially accountable health care}

The financing of socially accountable health care is crucial in the sense that the mandate for progressive, fundamental health reform lies in the control over financial resources in the health sector. Wolinsky $(1988,67)$ remarks: "It should become clear that the way to control the health care delivery system is to regulate the flow of money into and within the system... Therefore, if you want to control the system, you have to control the purse strings". With finer nuance as to the requirements of socially accountable health care in South Africa, De Beer $(1988,12)$ essentially holds the same opinion: "Firstly, there must be a single national structure responsible for the planning, co-ordination and implementation of health care. This structure and all its facilities must be integrated racially and ethnically and must eschew the artificial separation of preventive and curative services. Many of the activities currently carried out in the private sector will also need to be integrated into a nationally co-ordinate strategy. Secondly, the money used to finance health care should be collected and administered by the same central authority which is responsible for the planning and provision of health care..." Structural integration and organisational rationalisation of this nature could enhance social accountability in the sense of affordability in several ways provided, of course, that this central 
authority has no financial interest or commercial motives in the provision of health care. It should remain impartial and accountable only to the communities whose health needs and demands it has to provide. In this sense, Dodds' (1992, 14) remark on development in general also applies to health reform in particular: "We need a process that focuses on what people want and not on eliminating what they don't want... Such a process is one of interactive, participating national development planning, and should be conducted with the aid of facilitators who don't have a stake in the system short of seeing it succeed." The key to affordable health care ties in effective, efficient organisation and planning by a socially accountable financing agent - on condition, of course, that the profit motive and the idea of free-market health care are abolished.

\section{PROSPECTS FOR A SOCIALLY ACCOUNTABLE HEALTH CARE SYSTEM IN SOUTH AFRICA}

The aforementioned structural changes and rearrangements in the South African health care system should settle much of the present organisational confusion and financial waste and should render the system capable of providing socially accountable health care. Yet, regardless how clear the rationale and motivation for socially accountable health care may seem, the implementation of progressive reform towards its end may prove extremely difficult and problematic. This can be explained by the fact that the structural reform of the South African health care system according to the principles and requirements of social accountability implies different priorities, in health care than those currently prevailing.

Socially accountable health care indeed sees the various interests vested in current health care arrangements at stake. As regards medical practitioners, socially accountable health care requires re-orientation and reconsideration in their established work ethic, role definition and traditional professional values. For medical practitioners, the idea and requirements of socially accountable health care may constitute a challenge to established views regarding the nature of health care. Such views are cultivated by a free-market ideology, according to which the values of liberalism, individualism, private ownership, free enterprise, freedom of choice and contract, market entitlement, regulation through competition, profit making and material rewards for individual input are highly regarded (Fourie 1989, 137-142). The view is fostered that health care is a commodity to be traded at a profit in the free market, and can therefore be regarded as the privilege of those who can afford it and have earned their claim on health care. This ideological orientation benefits the medical profession in the sense that it allows them the privileges of health care provision in a free market - a high income level, social esteem and prestige, unhampered professional and clinical autonomy and a large degree of involvement in the deliberation of matters pertaining to health care. However, this orientation and approach towards health care runs counter to the notion of socially accountable health care based on a humanitarian approach, embracing values of altruism, equity, equality and justice and culminates in the recognition of health care as a basic human right. Prospects of an enforceable national health policy, the abolition of fee-for-service remuneration, centralised control and collective financing therefore may be expected to meet with opposition from professional ranks. Ugalde $(1979,109)$ explains: "In some societies in which a fee for service is the prevalent form of obtaining medical services, the medical profession has become a money aristocracy and has built powerful associations to retain its privileges when threatened by populations who consider access to medical services to be more a right than a privilege" (cf. Segall 1983, 1954).

For state and health authorities, social accountability requires acknowledgment and acceptance of an unavoidable responsibility for providing health care to the whole South African population. To understand their failure to do so, one has to realise that, in its role as facilitator of opposing interests, the state continuously attempts to maintain a precarious balance between the conflicting demands with which it is confronted. Opposing demands however, are considered and weighed within a power matrix eschewed by the state's interest in maintaining a socio-political order based upon a capitalist economy. For the state, the very issues of its legitimacy and power are at stake in the sense that the rationale for its existence and the basis of its power depend on a capitalist social order. In addition to protecting its legitimacy and power, the state also benefits from promoting measures and strategies conducive to the preservation of the status quo in the sense that it is exempted from a considerable financial and moral responsibility regarding the provision of health care, as well as from the blame should affairs in the health sector come under criticism.

Because the state and the medical profession constitute no mutual threat to each other, they form a close coalition when their interests are threatened or questioned. Those who threaten to overturn the political-economic and ideological order are denied access to the corridors of power and are reminded that the right of admission to positions of power is reserved for the guardians of capitalism. The state and medical profession have been lulling their sense of social responsibility by superficial changes in arrangements in the health sector and by ad hoc adjustments to problematic practices and priorities in South African health care. Continuous amendments to the Medical Schemes Act (72 of 1967) and numerous changes in the method of tariff determination for private health services substantiate the argument (Van Rensburg et al. 1992, 218-224). These are typical examples of what Waitzkin $(1983$, p.42) regards as "reformistic reform" - a concept he explains as follows: "Reformist reforms' provide small material improvements while leaving intact current political and economic structures. These reforms may reduce discontent for periods of time, while helping to preserve the system in its present form: 'A reformist reform is one which subordinates objectives to the criteria of rationality and practicability of a given system and policy...[I]t rejects those objectives and demands -however deep the need for them - which are incompatible with the preservation of the system'" (cf Lindblom 1979, 522). The effect of a reform process confined within the boundaries of a free-market capitalistic system is clearly observable in South African health care. An inability and reluctance to question and oppose vested interests have trapped health reform in a vicious cycle of reformism. The prejudice and overt antipathy against, the discreditation and ideological impeachment of, and even the sabotage of progressive reform initiatives are cases in point. One needs only ask what has become of the recommendations of various commissions of inquiry which have meticulously investigated several problematic aspects of South African health care. It appears that the politics of the free-market and the capitalist hegemony in health care have ensured that the recommendations of the National Health Services Commission of 1944 (or so-called Gluckman Commission), the Vos- (1925), Loram(1928), Collie- (1936) and Browne(1986) Commissions largely faded into obscurity (Van Rensburg et al. 1992, 
$60-64 ; 74-76)$. This observation is further substantiated by the persistent pursuit of a policy of privatisation amidst the curtailment of public health expenditure - contradictory to the clear need for different measures and strategies to address our health care problems.

\section{CONCLUSION}

Self-righteous professional, political and financial interests remain the sacred cows in the reform of South African health care. In fact, the South African health care system serves as reminder that social policy is much rather the outcome of prevailing wills, wishes and wants of the political and economic powers than it is a process conducive to and protective of the social interest. Health policy-making and health reform are political processes and therefore prospects for progressive health reform and socially accountable health care in South Africa are deemed unfavourable. Perhaps we are too pessimistic in our prospects for a socially accountable health care dispensation in South Africa and maybe our judgment of the various players in the field is too harsh. Yet, we tend to agree that Tannen's $(1980,118)$ verdict of the matter in the USA is equally applicable to South Africa: "Surely medical ideology is shaped and determined by many different forces and is not dictated by any one class, but of the many variations and different organizational forms possible, it is no accident that the prevailing form of medical practice today is largely compatible with the capitalist mode of production and its social relations, It would be highly unlikely for the medical system in this country to foster ideas relating to the social origins of disease, collective responsibility for health, democratization of medical skills, or community control of medical facilities, These concepts run counter to the prevailing values of the rest of society. " (Cf. Battistella \& Smith 1974, 707; Lindblom 1979，520-521; Navarro 1989，889; Roemer \& Roemer 1982, 112).

\section{REFERENCES}

ALLAN, J.D. \& B.A. HALL. (1988) "Challenging the focus on technology: A critique of the medical model in a changing health care system." Advances in Nursing Science 10(3):22-34.

BATTISTELLA, R.M. \& D.B. SMITH (1974). "Towards a definition of health service management: A humanist orientation." International Journal of Health Services 4(4):701-720.
BENATAR, S.R. (1988). "Medicine and health care in South Africa." Energos 15:21-28.

BENATAR, S.R. (1991). "Medicine and health care in South Africa - Five years later." New England Journal of Medicine 325(1):30-36.

BOTTOMORE, T., S NOWAK \& $M$. SOKOLOWSKA (Eds.). (1982). Sociology: The state of the art. Beverly Hills: SAGE.

BROOMBERG, J., C. DE BEER \& M.R. PRICE. (1990). "The impact of the fee-for-service reimbursement system on the utilisation of health services." South African Medical Journal 78(3):130-132.

BUCH, E. (1987). Towards a National Health Service - forward from the current situation: Current resources and their development. Johannesburg: Centre for the Study of Health Policy (Wits).

CENTRE FOR HEALTH POLICY. (1990). The great nationalisation debate: The case of private health care. Johannesburg: Centre for Health Policy (Wits).

CENTRE FOR HEALTH POLICY. (1991). An end to hospital apartheid? A case study of progress towards non-racialism. Johannesburg: Centre for Health Policy (Wits).

CENTRE FOR THE STUDY OF HEALTH POLICY. (1988). A national health service for South Africa. Part I. The case for change. Johannesburg: Centre for the Study of Health Policy (Wits).

CENTRE FOR THE STUDY OF HEALTH POLICY. (1989). Report on conference: Containing costs in health care: Towards affordable care for all. Johannesburg: Centre for the Study of Health Policy (Wits).

COE, R.M. (1978). Sociology of medicine. New York: McGraw-Hill.

COOPER, C., J. SCHINDLER, C. MCCAUL, P. BROUARD, C. MAREKA, J-M. SEIMON, M. MARKOVITZ, M. MASHABELA \& C. PICKARD-CAMBRIDGE. (1988a). Race relations survey 1986 Part 2 (Health). Johannesburg: South African Institute of Race Relations.

COOPER, C., J. SCHINDLER, C. MCCAUL, R. HAMILTON, M. BEALE, A. CLEMANS, L-M.
KRUGER, M. MARKOVITZ, J-M. SEIMON, P. BROUARD \& G. SHELTON. (1988b). Race relations survey 1987/88 (Health). Johannesburg: South African Institute of Race Relations.

COOPER, C., J. SCHINDLER, C. MCCAUL, R. HAMILTON, M. BEALE, A. CLEMANS, L-M. KRUGER, I. DELVARE \& J.G. MOONSAMY. (1989). Race relations survey 1988/89 (Health). Johannesburg: South African Institute of Race Relations.

COOVADIA, H.M. (1991). The quest for health, development and democracy. Professorial inaugural lecture. Durban: University of Natal. 8 May 1991.

DE BEER, C. (1988). Some aspects of the political economy of health care in South Africa: The need for a National Health Service. Johannesburg: Centre for the Study of Health Policy (Wits).

DEPARTMENT OF NATIONAL HEALTH AND POPULATION DEVELOPMENT. (1988). Health trends in South Africa. Pretoria: Department of National Health and Population Development.

DEPARTMENT OF NATIONAL HEALTH AND POPULATION DEVELOPMENT. (1991). Health trends in South Africa. Pretoria: Department of National Health and Population Development.

DEWAR, S.R. (1990). Nursing in crisis: Problems, solutions (a synthesis). Durban: University of Natal (Department of Nursing).

DODDS, M. (1992). "Development: A challenge to power and politicians." Democracy in Action 6(5):10-14.

ELLING, R.H. (1974). "Case studies of contrasting approaches to organizing for health: An introduction to a framework." Social Science and Medicine 8:263-270.

FOURIE, A. (1989). "Die mediese professie en sosiale verantwoordelikheid: 'n Kritiese beskouing in die lig van die Suid-Afrikaanse gesondheidsorgproblematiek." Acta Academica 21(4):128-147.

KELLY, J. (1988). "The politics of health care in South Africa: A general overview." Con-text 1:115-130. 
KLOPPER, J.M.L., D.E. BOURNE, D.E. MCINTYRE, W.M. PICK \& S.P. TAYLOR. (1899). "A methodology for resource allocation in health care for South Africa." South African Medical Journal 70(5):293-295.

LINDBLOM, C.E. (1979). "Still muddling, not yet through." Public Administration Review (Nov/Dec): 517-526.

MAYNARD, A. (1986). "Public and private sector interactions: An economic perspective." Social Science and Medicine 22(11):1161-1166.

NAVARRO, V. (1989). "Why some countries have National Health Insurance, others have National Health Services and the US has neither." Social Science and Medicine 28(9):887-898.

NAYLOR, C.D. (1987). "Privatisation of South African health care - are the underlying assumptions correct? South African Medical Journal 72(10):673-678.

NAYLOR, C.D. (1988). "Private medicine and the privatisation of health care in South Africa." Social Science and Medicine 2(11): 1153-1170.

PRESCOTT, N. \& D. DE FERRANTI. (1985). "The analysis and assessment of health programs." Social Science and Medicine 20(12):1235-1240.

PRICE, M. (1987). "Health care beyond apartheid." Critical Health. Dissertation 8.

REPUBLIC OF SOUTH AFRICA. (1988/89). South Africa. Official yearbook of the Republic of South Africa. Pretoria: Government Printer.

REPUBLIC OF SOUTH AFRICA. (1990/91). South Africa. Official yearbook of the Republic of South Africa. Pretoria: Government Printer.

ROEMER, M.I. \& J.E. ROEMER. (1982). "The social consequences of free trade in health care: A public response to orthodox economics." International Journal of Health Services 12(1):111-129.

ROSEN, B. (1989). "Professional reimbursement and professional behaviour: Emerging issues and research challenges." Social Science and Medicine 29(3):455-462.

SAVAGE, M.T.D. (1986). "Health." RSA 2000 8(1):60.

SAVAGE, M.T.D. \& S.R. BENATAR. (1990). "Analysis of health and health services." 147-167 in Critical issues for South Africa: An agenda for the 1990's, ed. by R.A. Schrire. Cape Town: Oxford University Press.

SCHRIRE, R.A. (ed.) (1990). Critical issues for South Africa: An agenda for the 1990's. Cape Town: Oxford University Press.

SEGALL, M. (1983). "Planning and politics of resource allocation for primary health care: Promotion of meaningful national policy." Social Science and Medicine 17(24): 1947-1960.

TANNEN, L. (1980). "Health planning as a regulatory strategy: $A$ discussion of its history and current uses." International Journal of Health Services 10(1):115-131.
TWADDLE, A.C. (1982). "From medical sociology so the sociology of health: Some changing concerns in the sociological study of sickness and treatment." 323-358 in Sociology: The state of the art, ed. by Bottomore, T., S. Nowak \& M. Sokolowska. Beverly Hills: SAGE.

UGALDE, A. (1979). "The role of the medical profession in public health policy making: The case of Colombia." Social Science and Medicine 13C(2):109-119.

VAN RENSBURG, H.C.J., E. PRETORIUS \& A. FOURIE. (1992). Gesondheidsorg in Suid-Afrika: Struktuur en dinamika. Pretoria: Academica.

WAITZKIN, H. (1983). The second sickness: Contradictions of capitalist health care. New York: The Free Press.

WOLINSKY, F.D. (1988). The sociology of health: Principles, practitioners and issues. Belmont: Wadsworth.

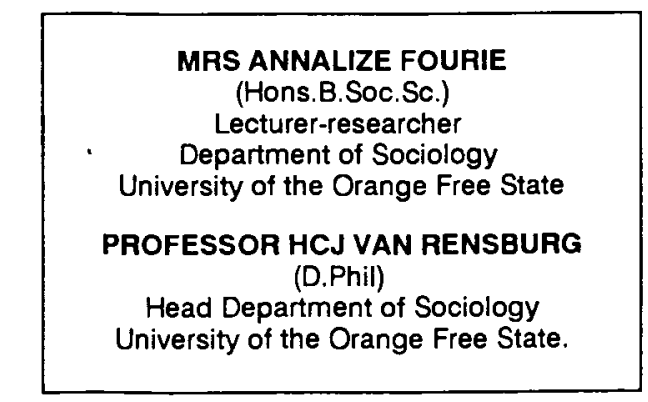

